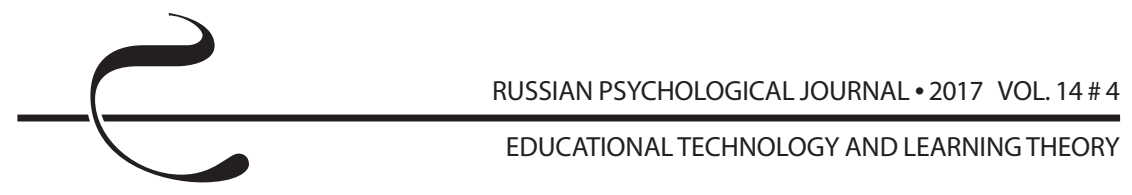

UDC 371.13:323.11

DOI: $10.21702 /$ rpj.2017.4.12

\title{
Strengthening the Pre-Service Teacher Training System in a Multi-Ethnic Society
}

\author{
Valentina Gulevska ${ }^{1}$, Alma Tasevska ${ }^{2}$, Snezana Jovanova Mitkovska ${ }^{3}$, Lulzim Ademi², \\ Vesna Makasevska ${ }^{2}$, Kustrim Ahmeti ${ }^{4}$, Jelena Brajovikj \\ 1 University "St. Kliment Ohridski", Bitola, Macedonia \\ ${ }^{2}$ University "Ss. Cyril and Methodius", Skopje, Macedonia \\ ${ }^{3}$ University "Goce Delcev", Stip, Macedonia \\ ${ }^{4}$ University of Tetovo, Tetovo, Macedonia \\ *Correspondence author. E-mail: valentina.gulevska@uklo.edu.mk
}

\begin{abstract}
Introduction. The difference which nature has placed between one man and another is so wide. Also, the difference which comes by religion, cultural habits and similar elements in the human life can be further enlarged by education. During the last ten years, interethnic relations in Macedonian educational system become central topic for the activity of educational policy makers. In that line, the novelty of this research lies in the designing of student practicum by making cross-cultural contacts in the sphere of education.
\end{abstract}

Methods. Macedonian government's programs and legal framework promote interethnic communication, but implementation of principles as respect, tolerance, and acceptance in the school life still is reduced only on using different languages of ethnic communities in teaching process. At the same time, appears the need to enhancing teachers' capacities for work in a multicultural environment and ensuring all children receive a high-quality education.

Results. The results of the research show that informal education activities can encourage a thinking process as intellectual instrument for extermination prejudices related interethnic communication through the closer contact and interaction between the students, teachers and parents in the school environment.

Discussion. It is certainly very difficult to set balancing between variety of behaviours, dictated by the presumed needs of specific cultures, religions and beliefs, but the classroom should be common home for all students and the teacher should know to manage such relationship.

\section{Keywords}

multi-ethnic society, education, teachers, competencies, student practicum, informal education, project activities, evaluation, curriculum, educational policy 


\section{Highlights}

- The student practicum in the NGO sector and in a multicultural environment can enhance the capacity of the prospective pedagogues, teachers and other educators for working in multicultural environment.

- The category of participating students shows a higher degree of development of competences for work in multicultural environment than the category of students who did not participate in the project.

- The category of participating students show an evident tendency to open up to people with different experience and ethnic background, make new acquaintances, and in general, communicate without prejudice than the category of students who did not participate in the project.

\section{For citation}

Gulevska V., Tasevska A., Mitkovska S. J., Ademi L., Makasevska V., Ahmeti K., Brajovikj J. Strengthening the Pre-Service Teacher Training System in a Multi-Ethnic Society. Rossiiskii psikhologicheskii zhurnal - Russian Psychological Journal, 2017, V. 14, no. 4, pp. 243-266 (in Russian).

Original manuscript received 18.05.2017

\section{Introduction}

The pedagogical science commonly acknowledges that the global concept of multicultural education is mainly characterized by the following parameters: strengthening of the teacher intercultural competencies, curriculum reforms of the teacher training faculties, promotion of pedagogy of equality and education for social equity. The higher education also has become with visible international dimension [1].

The intercultural competencies of the teachers are acquired and developed over a long process of education and professional development, during which the teacher is trained to acknowledge the multicultural principles in the education and resolve problems related to the cultural diversity in the educational process [2]. The curriculum reforms of the teacher training faculties are closely aligned to these educational trends and revealing society as a culprit minimizes the potential for "blaming the victim" [3]. In addition to the new multicultural education content, the teacher training syllabus requires further interventions into the relevant literature (textbooks, teacher aids and other type of educational material used by the teachers and the students). The basic curriculum reform impetus is the promotion of the pedagogy of equality [4]. This type of pedagogy aims at creation of equal possibilities for all children, regardless of their religion or ethnic affiliation. The education for social equity, on the other hand, works towards strengthening the teacher knowledge about the structure of the multiethnic societies and helps develop capabilities and skills for social action and 


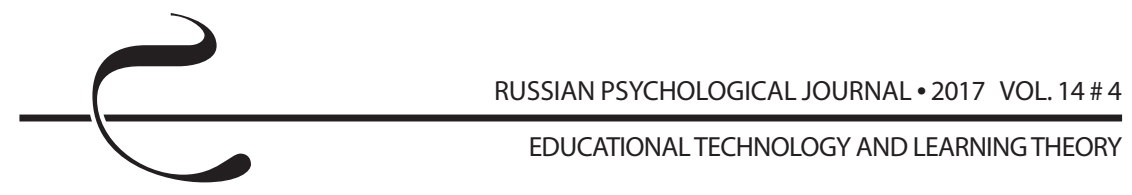

cohesion. Therefore, "multicultural literature is essential to all areas of the curriculum to help students grow in understanding of themselves and others" [5].

In this regard, the intercultural and interethnic relations in the education system of the Republic of Macedonia systematically impose the need for constructive communication and interaction, in line with the contemporary education trends. For example, Patricia G. Ramsey [6] describes how the heavy and controversial issues of oppression, exploitation, and social justice may seem to be a world away from young children. Also, other experts agree that culturally responsive teacher must encourage all students to have high personal expectations regardless their cultural backgrounds [7]. The implementation of such educational goals and priorities requires adequate knowledge, skills and mindset of the teachers. Therefore, experts claim that culturally competent teachers are the most powerful workforce for balancing the differences in a rapidly changing world [8].

The teaching staff in the country is educated in a number of higher education institutions: Skopje Faculty of Pedagogy "St. Kliment Ohridski", Bitola Faculty of Education, Stip Faculty of Educational Sciences, Institute for Pedagogy with the Faculty of Philosophy in Skopje and the Institute for Pedagogy with the Faculty of Philosophy in Tetovo. These institutions primarily produce teaching staff in three degrees of education (preschool, primary and high school).

The education of the prospective educators, teachers and pedagogues, pays particular attention not only to the theoretical knowledge, but also to the practical skills. Given that the multicultural modules in the higher education have thus far been treated primarily from a theoretical and academic point of view, the Education Section of the OSCE Mission to Skopje, has introduced both theoretical and practical elements, notably through a series of modules and activities as part of the so called informal education, i. e. trainings and seminars, intended for students and teaching staff. At the same time, all teacher training faculties have recognized that the future teachers and pedagogues should acquire a deep sense of empathy and concern for the well-being of all children [9].

In addition to initiating joint work and friendships of students with different cultural and ethnic background, other successful activities have been implemented, including: trainings and seminars for students of all five faculties (in a 7-year period), creation and development of a Manual with multicultural content intended as an additional literature for the students, and for the higher education professors dealing with this issue, development of an Instruction for Implementation of the Practicum, intended for professors-mentors, educators/teachers-mentors and students, organization of international conferences on the subject of: Practicum and challenges of prospective pedagogues, teachers and educators in multicultural environments.

The above activities are a result of the excellent cooperation between the faculties of pedagogy and philosophy in the country. Of note is that the Manual 
for Social Skills and Responsibilities of the Teachers and the Associates in the School and the Instruction for Implementation of the Student Practicum have provided an exceptional contribution to the creation of the basic direction for this educational tendency, whereas the conclusions of the OSCE-supported international conference, organized by all teacher training faculties, have supported the sustainability of the approach to the issues of multiculturalism in the education system of the Republic of Macedonia. On this way the future teachers and pedagogues can accept "a shift towards value neutrality" [10, p. 45], i. e. they can inspire young people to further learning and activism [11].

\section{Methods}

\section{Subject of the research}

Subject of this research are:

- the syllabus of the teacher training faculties in the Republic of Macedonia, with regard to the inclusion of multicultural content;

- the perceptions of the students at the faculties of philosophy and pedagogy in the Republic of Macedonia on the inclusion and the implementation of multicultural content in their faculty syllabuses and the effects of the implementation of the activities from the project Strengthening the Pre-Service Teacher Training System in a Multi-Ethnic Society;

- the opinions and the experience of the teachers at the faculties of philosophy and pedagogy from the countries in the region with regard to the inclusion of multicultural content in the syllabuses, involvement of students in projects on multicultural education as well as the implementation of the practicum in a multicultural environment.

\section{Goals and type of the research}

The research aimed at providing a comparative overview of the syllabuses of the teacher training faculties in the Republic of Macedonia and select countries in the region. The research particularly focused on the extent of inclusion of multicultural content and analysis of the effects from the implementation of the activities of the project Strengthening the Pre-Service Teacher Training System in a Multi-Ethnic Society, aiming at development of intercultural competencies of the prospective pedagogues, teachers and educators.

This is a contemporary research, as it deals with the current issue of pedagogic practice, by applying a transversal, empirical, descriptive, qualitative and quantitative approach. We consider that the application of the qualitative and the quantitative approach, along with the appropriate research techniques will contribute to obtaining detailed and essential analysis and interpretation of the data. 


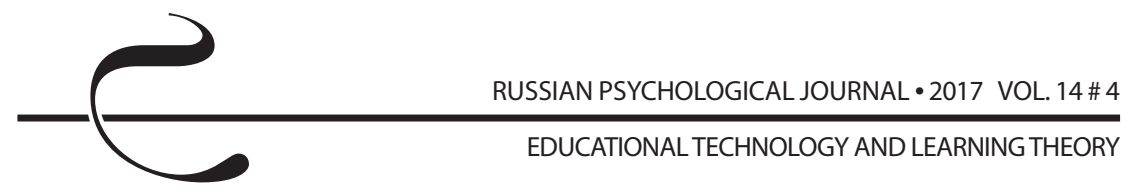

\section{Tasks of the research}

1. To analyze the syllabuses of the faculties of philosophy and pedagogy in the Republic of Macedonia, with respect to:

- mandatory subjects, inclusive of multicultural content;

- optional subjects, inclusive of multicultural content;

- subjects with potential multicultural content.

2. To review the student perception of the faculties of philosophy and pedagogy in the Republic of Macedonia, with respect to:

- participation in projects in the sphere of multicultural education;

- development of intercultural competencies;

- strategies in the implementation of the practicum in a multicultural context.

3. To review the perceptions and the experiences of the professors from the faculties of philosophy and pedagogy from the Balkans, with respect to:

- inclusion of multicultural content in the syllabuses;

- organization of a student multicultural practicum;

- participation of the students in projects dealing with multicultural education.

\section{Hypotheses}

Key Hypothesis: the implementation of the activities of the project Strengthening the Pre-Service Teacher Training System in a Multi-Ethnic Society has a positive effect on the further development of the intercultural competencies of the prospective pedagogues, educators and teachers.

Specific Hypotheses:

1. Hypothesis A (refers to the syllabuses of the faculties of philosophy and pedagogy in the Republic of Macedonia): multicultural modules in the syllabuses of the faculties of philosophy and pedagogy in the Republic of Macedonia are generally offered as optional subjects.

2. Hypothesis B (refers to the students of the faculties of philosophy and pedagogy in the Republic of Macedonia): the bulk of the interviewees believe that the participation in projects related to multicultural education positively impacts the development of their intercultural competencies and prepares them for work in a multicultural environment.

3. Hypothesis $C$ (refers to the perceptions and the experiences of the professors from the faculties of philosophy and pedagogy from the countries in the region): the bulk of the interviewees share the opinion that the syllabuses of their faculties include modules on multicultural education, but also consider that there is a need for additional pedagogic practicum in a multicultural environment.

\section{Methods, Techniques and Instruments of the Research}

This research applies the comparative and the descriptive method as well as 
the theoretical analysis method.

The data was acquired through the following techniques and instruments: analysis of content and polling, i. e. registration sheet and two questionnaires administered to the students and the professors respectively.

\section{Representative Sample}

The research includes several samples:

- sample of students - participants in the project Strengthening the Pre-Service Teacher Training System in a Multi-Ethnic Society;

- sample of students - not participating in the same project;

- sample of professors from the faculties of philosophy and pedagogy in the Balkans.

\section{Results}

\section{Analysis of the syllabuses of the faculties of pedagogy and philosophy in} the Republic of Macedonia

The experts think that "redefined multicultural education must reflect changes in curriculum, teaching strategies, and school culture, as well as policy and administrative issues" [12, p. 61]. In that line, the research has started with analysis of the syllabuses.

The Table 1 below provides an overview of the extent of inclusion of multicultural modules in the syllabuses of all teacher training faculties.

The analysis of Table 1 shows that 28 mandatory and 44 optional subjects of the syllabus include multicultural education modules.

Table 1. List of mandatory and optional multicultural modules

\begin{tabular}{|c|c|}
\hline \multicolumn{2}{|c|}{ Faculty of Pedagogy "St. Kliment Ohridski”, UKIM, Skopje } \\
\hline $\begin{array}{l}\text { Mandatory subjects: } \\
\text { Sociology of Education; } \\
\text { Family Pedagogy; } \\
\text { History }\end{array}$ & $\begin{array}{l}\text { Optional subjects: } \\
\text { Multicultural Education; } \\
\text { Religious Systems; } \\
\text { Pedagogic Communication; } \\
\text { Communicology; } \\
\text { National History }\end{array}$ \\
\hline \multicolumn{2}{|c|}{ Faculty of Education, UKLO, Bitola } \\
\hline $\begin{array}{l}\text { Mandatory subjects: } \\
\text { Pedagogy; } \\
\text { Fundamentals of Democracy; } \\
\text { Sociology of Education; } \\
\text { Philosophy of Education }\end{array}$ & $\begin{array}{l}\text { Optional subjects: } \\
\text { Methodology of Educational Work; Ethics; } \\
\text { Comparative Religious Systems; } \\
\text { Culture of Expression; } \\
\text { History; Our Homeland; Culture and } \\
\text { Communication }\end{array}$ \\
\hline
\end{tabular}




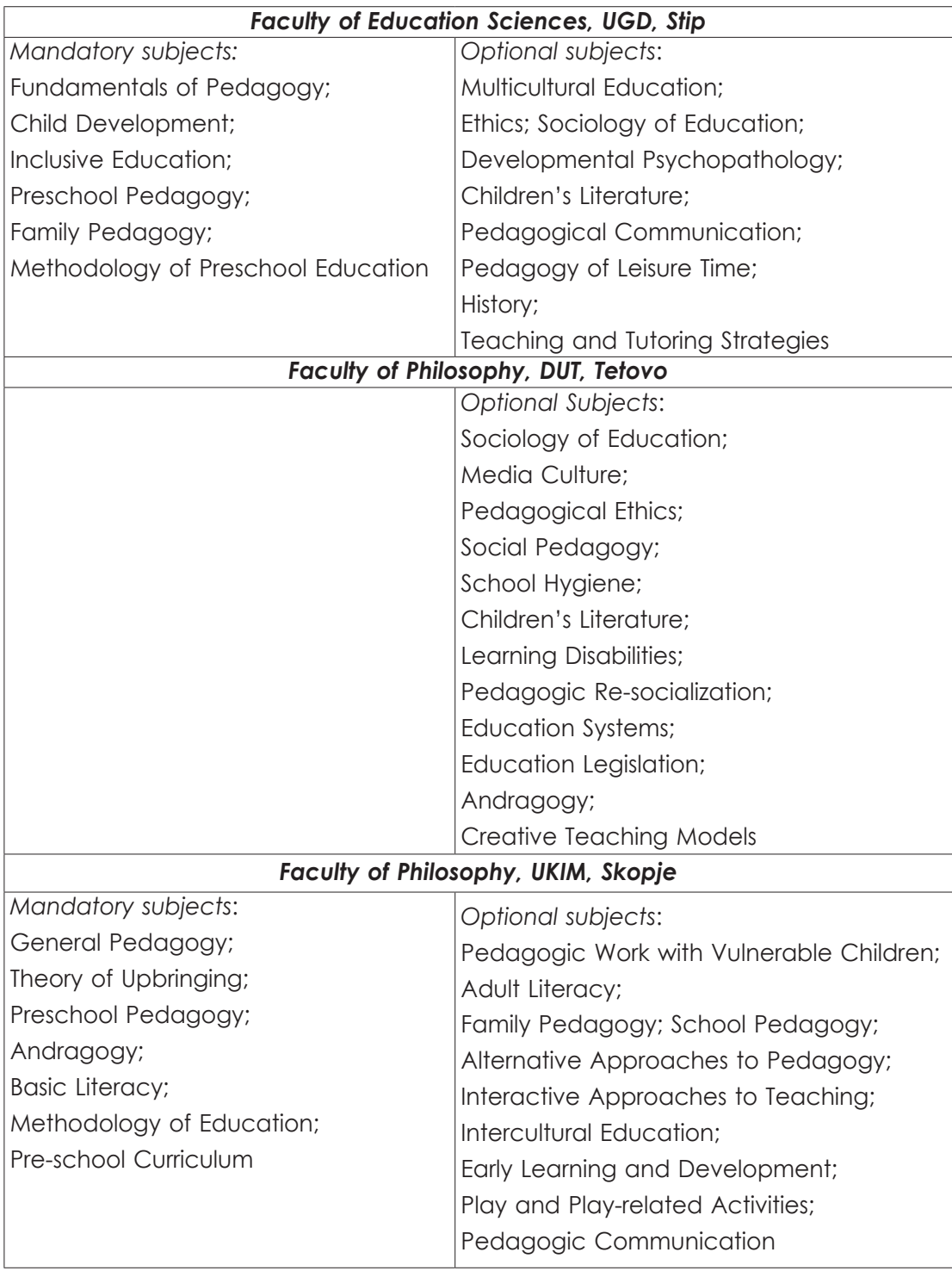

The pivotal subject Intercultural/Multicultural Education, which principally deals with multiculturalism, is predominantly offered as an optional subject in the teacher training syllabus. This subject aims to sensitize students for work in multicultural environment; familiarize them with the basic terminology and 
principles of multicultural education; provide them with skills for development of curriculum tailored for multicultural environment. Content-wise, the subject mainly refers to the societal role of education, the intercultural education as a global phenomenon, education in multicultural society, the relations between the different cultures and the education, education as a process of acquiring intercultural competencies, curriculum design in intercultural and multicultural context, and the role of the family and the education institutions. The professors from the faculties of philosophy and pedagogy in the Republic of Macedonia deem that the content of the aforementioned subjects may be additionally improved and the general and the specific descriptors further developed. Also, a commonly accepted opinion is that multicultural content may be incorporated in the remainder of the subjects, if not in the entire syllabus.

Table 2 provides a list of subjects which, according to the professors, may include modules with multicultural content.

Table 2. List of subjects which may include modules with multicultural content

Subjects which can potentially develop modules with multicultural content

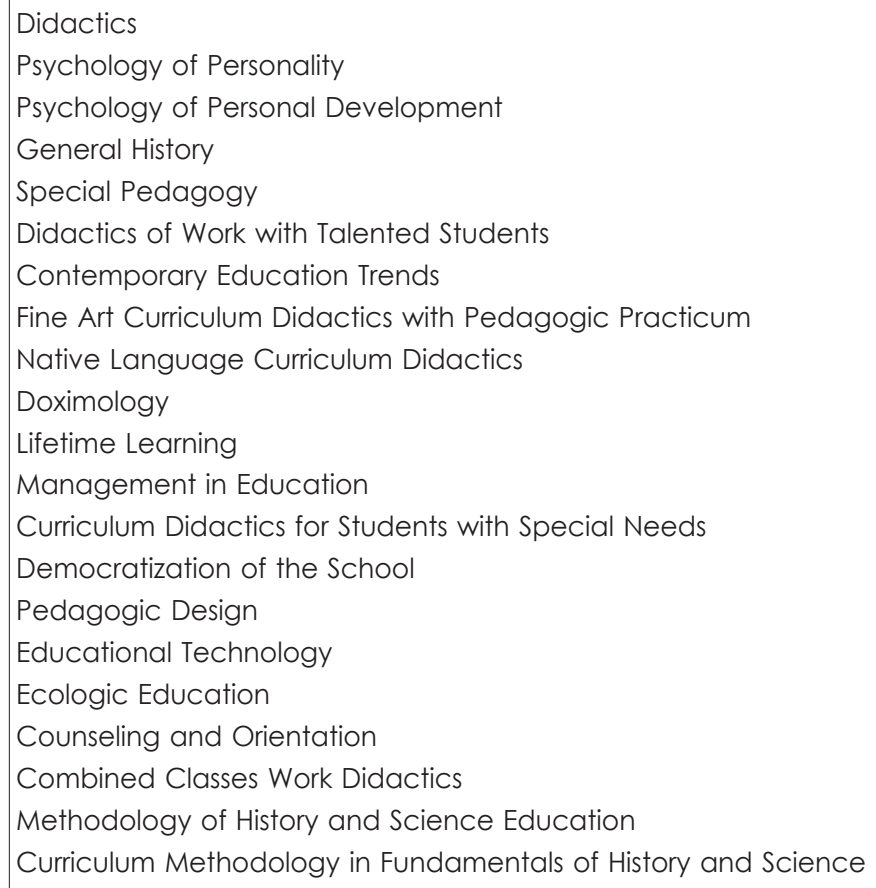


The Figure 1 shows that the multicultural education content is more represented in the optional than in the mandatory subjects.

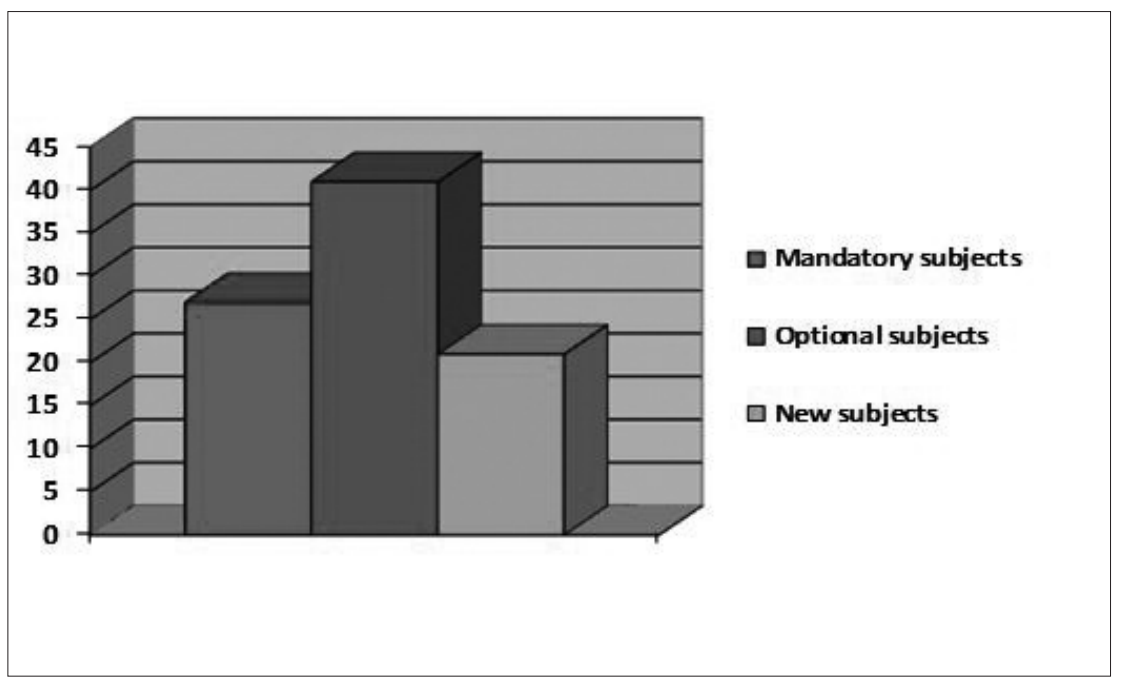

Figure 1. Overview of mandatory and optional subjects with multicultural content and new subjects which carry the potential of including multicultural content

Additionally, at the teacher training faculties, many subjects can potentially develop modules with multicultural content.

In the future, based on the data and the current affairs in the sphere of teacher training, the relevant agencies in charge of creation and development of national education policies may propose further interventions in the syllabus with regard to the mandatory subjects.

\section{Analysis of the student perceptions from the faculties of philosophy and pedagogy in the Republic of Macedonia}

The survey was conducted among students of five higher education institutions in the Republic of Macedonia (Skopje Faculty of Philosophy, Tetovo Faculty of Philosophy, Skopje Faculty of Pedagogy, Bitola Faculty of Education and Štip Faculty of Educational Sciences). The representative sample comprises 198 interviewees. Of the total number of surveyed students in the project Strengthening the Pre-Service Teacher Training System in a Multi-Ethnic Society, 93 had taken part in the project as opposed to 105 interviewees who had not. The Figures 2, 3 and 4 show the gender, the ethnicity and the confessional structure of the interviewees. 


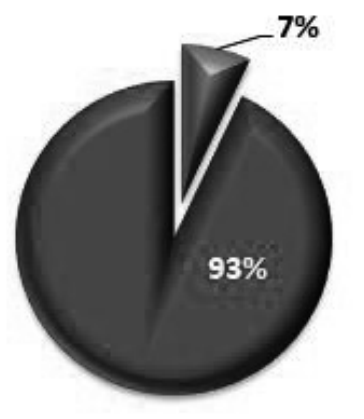

Male

日 Female

Figure 2. Gender structure of the interviewees

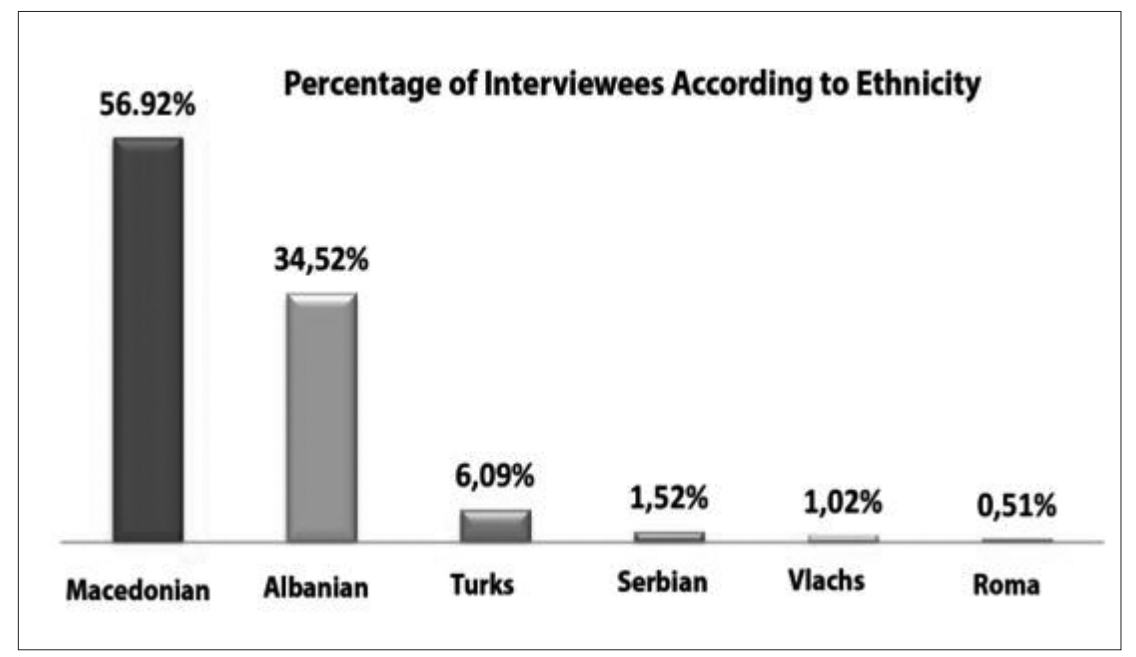

Figure 3. Overview of the ethnicity of the interviewees

Of the total number of surveyed interviewees (198), 14 are male, and 184 are female. With regard to the ethnicity of the interviewees, in the category of students participating in the project - 47 are e-Macedonian, 34 e-Albanian, eight e-Turks, three e-Serbs and one e-Roma. In the category of students not participating in the project - 64 are e-Macedonian, 34 are e-Albanian, four are e-Turks, two are e-Vlach and one interviewee is a member of another ethnic group, or a total of 


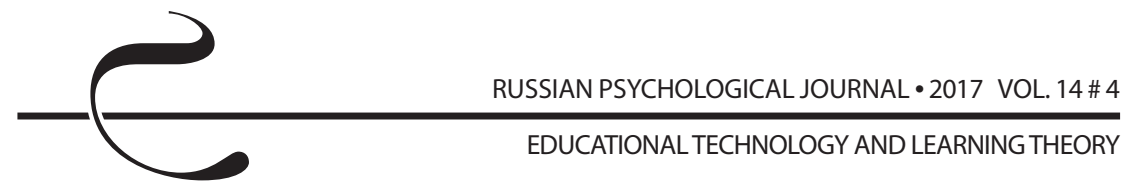

111 interviewees are e-Macedonian, 68 e-Albanian, 12 e-Turk, three are e-Serb, two e-Vlachs, one is e-Roma and one is a member of another ethnic community. The Figure 3 shows the ethnic structure of the interviewees in percentages.

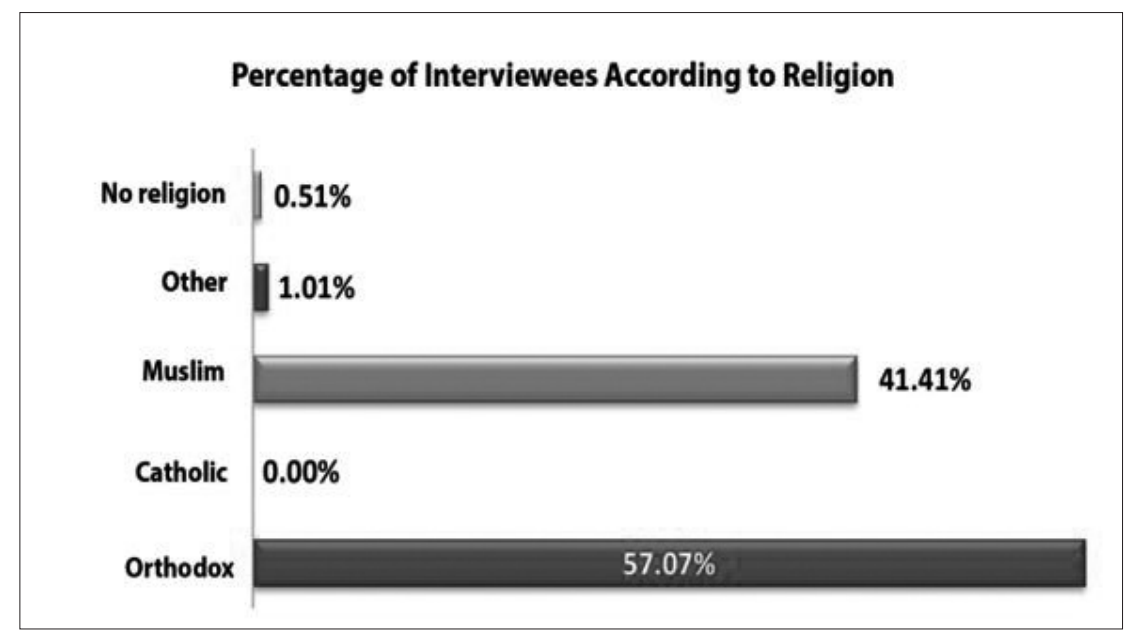

Figure 4. Overview of the religion of the interviewees

Of the total number of interviewees from the category of students participating in the project - 49 have declared themselves Orthodox Christian, 43 Muslims and one interviewee - a member of another religion. In the category of students not participating in the project - 64 have declared themselves Orthodox Christians, 39 Muslims, one interviewee a member of another religion and one without a religion. Of the total number of interviwees - 113 are Orthodox Christian, 82 are Muslims, two are members of another religion and one interviewee is without a religion. In the Figure 4, the confessional structure of the interviewees is shown in percentages.

Of the total number of interviewees - 113 students had participated in other education projects with multicultural component, as opposed to 85 who had not participated. Of the category of students participating in the project - 79 interviewees had participated in other education projects with multicultural component, as opposed to 14 non-participating interviewees. In the category of students not participating in the project, 34 interviewees had participated in other education projects with multicultural component, and 71 interviewees had not participated. The Figure 5 shows the percentage of interviewees - participants or non-participants - in other education projects with multicultural component. 


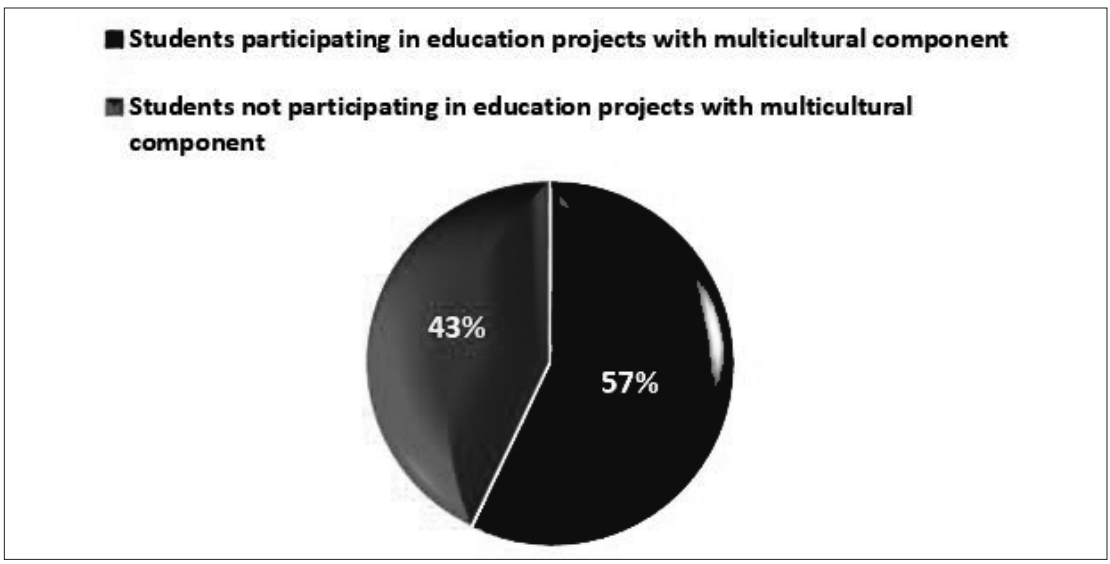

Figure 5. Overview of interviewee participation in other multicultural projects

The cross-cultural contacts in the sphere of education impose the need for constructive communication, which also has an impact on the role of the teacher in the educational process. It is also a demand of effective, empowering and transformative teaching [13]. The teacher typically carries along paradigms of education strategies and characteristics of his/her own community. The new societal trends require that the teacher's method of work undergoes changes [14]. The teacher increasingly acquires a role of a mediator among the students and deals with their specific expectations and needs in line with their different cultural traditions. According to the savants, the educational pluralism aims to build positive relations and relationships between the students through building mutual respect and acceptance of the others, the way they are, through setting joint goals as well as overcoming stereotypes and prejudice [15]. In order to examine the key hypothesis, i. e. the claim that the implementation of activities as part of the project Strengthening the Pre-Service Teacher Training System in a Multi-Ethnic Society positively affects the development of intercultural competencies of the prospective pedagogues, educators and teachers. The Figure 6 and 7 provide a comparative overview of the responses of the two categories of students to the following question: "Do you have friends of different cultural and ethnic background"? The students participating in the project have a significant number of friends with different cultural and ethnic background, unlike the students not participating in the project. For instance, in the latter category, 21 interviewees (or $20 \%$ of the students) have declared that they have no friends of different cultural and ethnic background, unlike the category of 
students participating in the project where only one interviewee has declared to have no friends of different cultural and ethnic background.

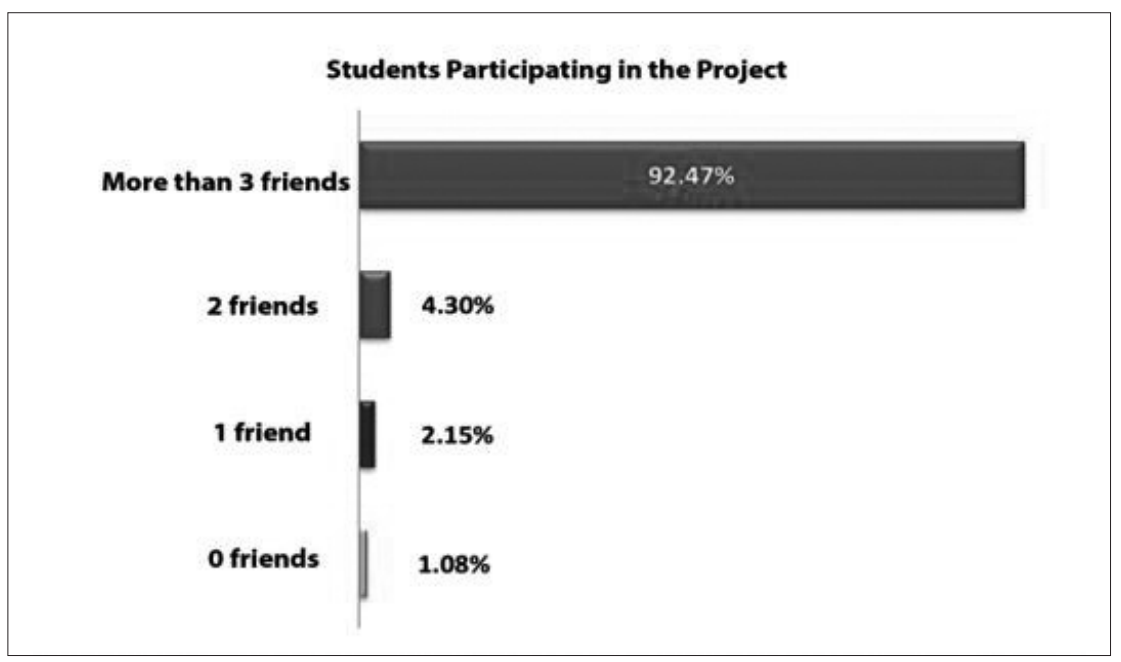

Figure 6. Overview of responses of students participating in the project to the question: Do you have friends of different cultural and ethnic background?

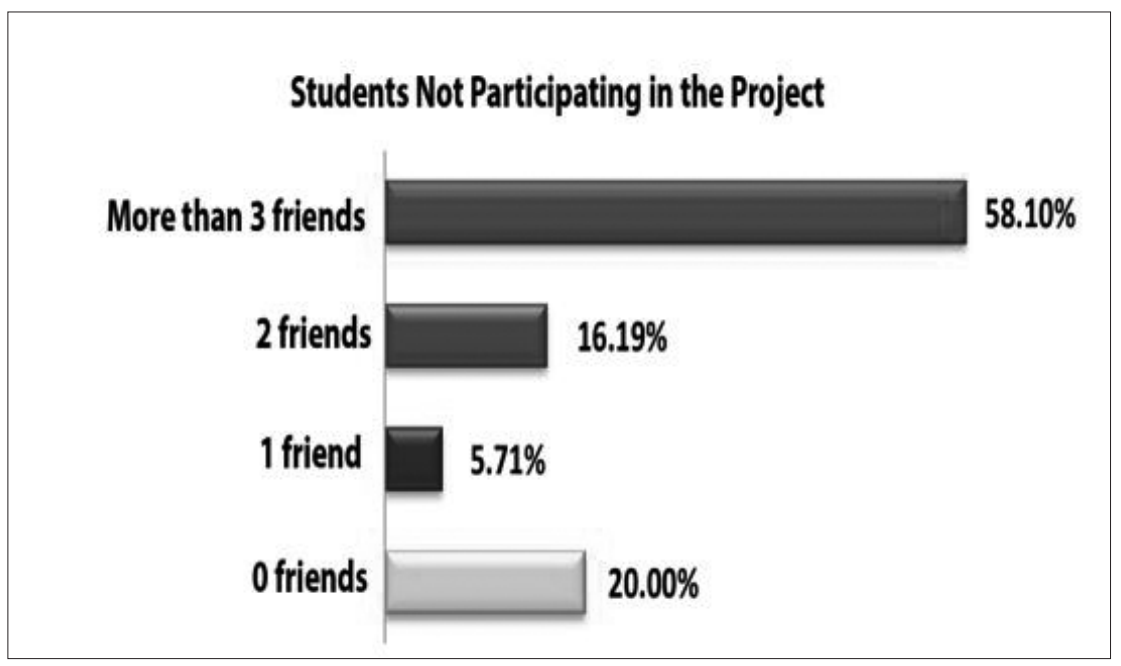

Figure 7. Overview of responses of students not participating in the project to the question: Do you have friends of different cultural and ethnic background? 
In order to reexamine the key hypothesis, i. e. the claim that the implementation of activities as part of the project Strengthening the Pre-Service Teacher Training System in a Multi-Ethnic Society positively affects the development of intercultural competencies of the prospective pedagogues, educators and teachers, the Figures 8 and 9 provide a comparative overview of the responses of the two categories of students to the following question: "Would you be willing to meet people with different cultural and ethnic background"? The students who participated in the project would like to meet people with different cultural and ethnic background more than the students who did not participate in the project. For instance, in the latter category, 57 interviewees (or 54,29 \%) have declared that they are always willing to meet people with different cultural and ethnic background, unlike the category of students participating in the project where 70 interviewees (or 75,27 \%) have declared that they are always willing to meet people with different cultural and background. Another interesting fact is that from the category of students not participating in the project two interviewees (or 1,90\%) have responded to have never been willing to meet people with different cultural and ethnic background, unlike the category of students who participated in the project where no interviewee (or 0,00\%) has responded to have never be willing to meet people with different cultural and ethnic background.

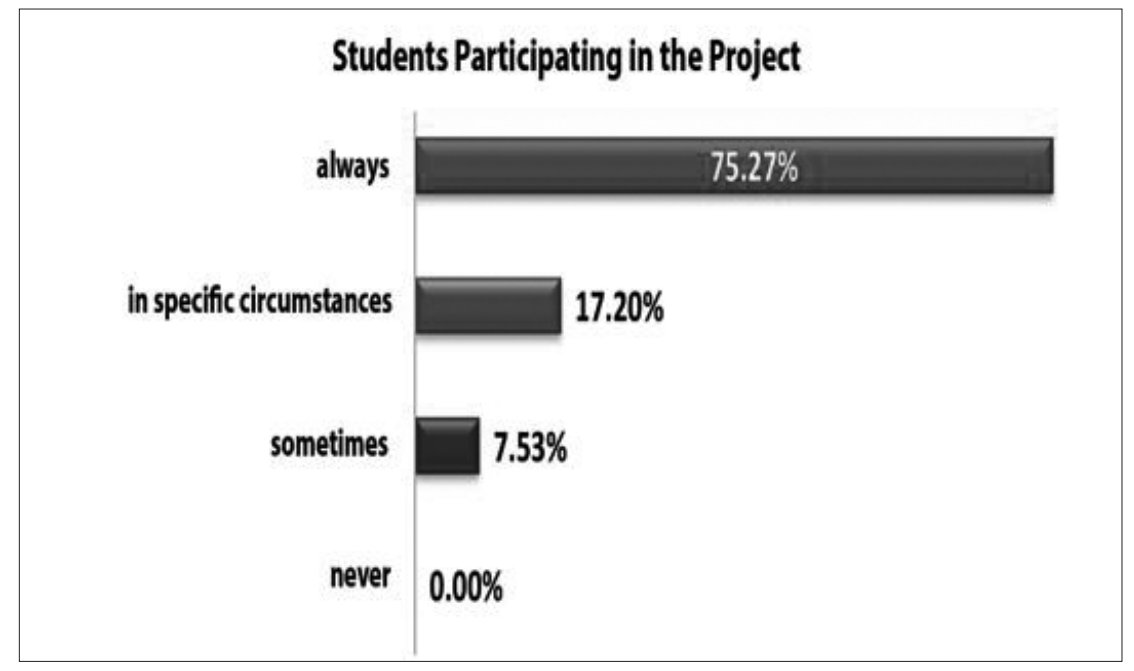

Figure 8. Overview of responses of students participating in the project to the question: Would you be willing to meet people with different cultural and ethnic background? 

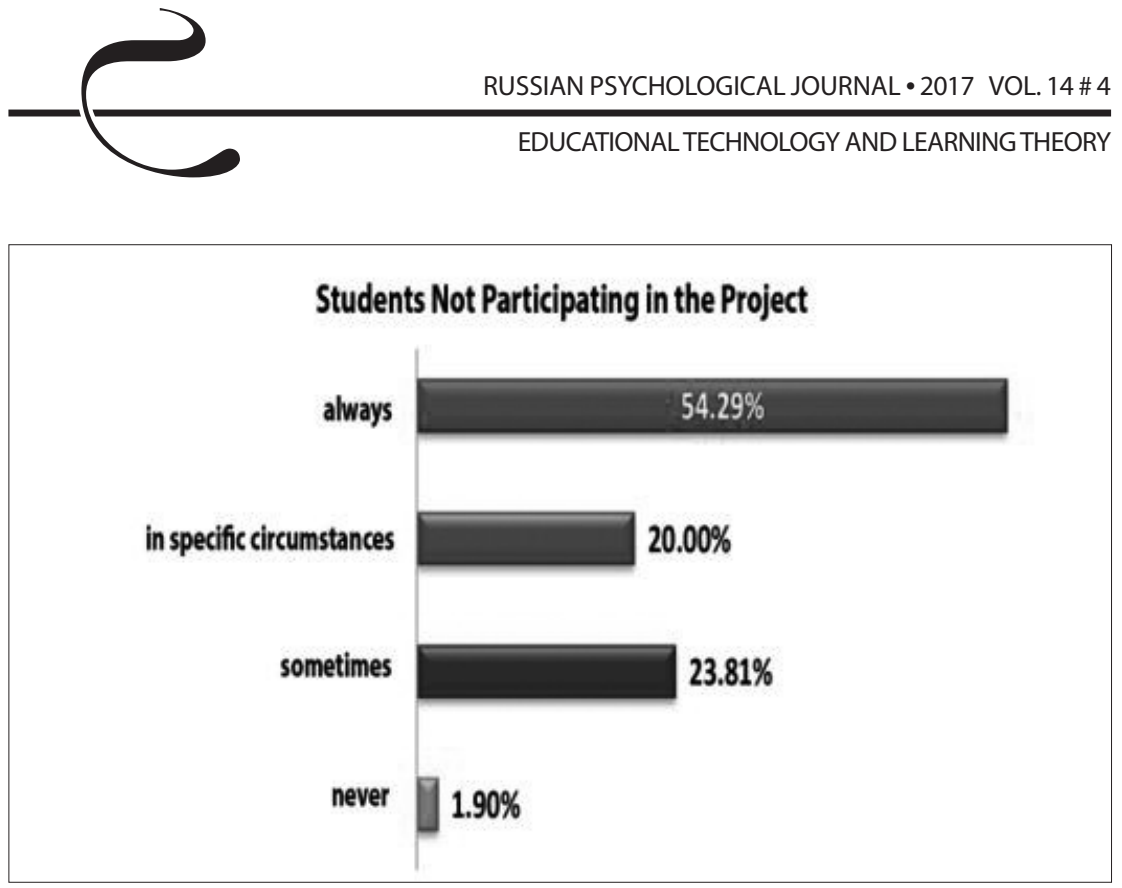

Figure 9. Overview of responses of students not participating in the project to the question: Would you be willing to meet people with different cultural and ethnic background?

To examine the impact of the project Strengthening the Pre-Service Teacher Training System in a Multi-Ethnic Society on the development of the intercultural competencies of the students who participated in the project activities, the questionnaire offered ten key intercultural competencies on which the students were asked to provide their opinion with regards to the degree of its adoption. The premise is that the category of students participating in the project will have acquired these competencies to a larger degree compared to the category of students not participating in the project. The key intercultural competencies are described comparatively in the Figure 10 and 11. The overview upholds the specific hypothesis $A$, according to which, the interviewees have the opinion that the participation in education projects with multicultural component positively affects the development of their intercultural competencies and prepares them for work in a multicultural environment. Of the offered ten intercultural competencies, students participating in the project (72 students or $77,42 \%$ ) consider that they have mostly developed the second competency, i. e. that they had acquired a skill to respect the diversity with regard to the culture, gender, ethnic and social affiliation. Students not participating in the project (61 student or $58,10 \%$ ) consider that they have mostly developed the fourth competency, i. e. the willingness to build positive and friendly relationships with colleagues of different cultural and ethnic background. 


\section{Competencies Acquired During Implementation of Pedagogic Practicum} I have capacity to express empathy
and promote social justice

I'm prepared for self-reflection and reassessing personal steotypes and prejudices

I'm prepared to contribute to raising student awareness on the neccessity of their inclusion in the democratic processes

I'm qualified to contribute to overcoming discrimination in schools

I'm qualified to contribute to classroom conflict resolution

I'm qualified to cooperate with social institutions and NGOS

I'm prepared to build positive and friendly relations with colleagues of different cultural and ethnic background

I'm prepared to contribute to prevention of violence in schools

I respect diversity with regard to cuture, gender, ethnic, and social affiliation

Through personal example I stand for the Idea of equal access to education for all children
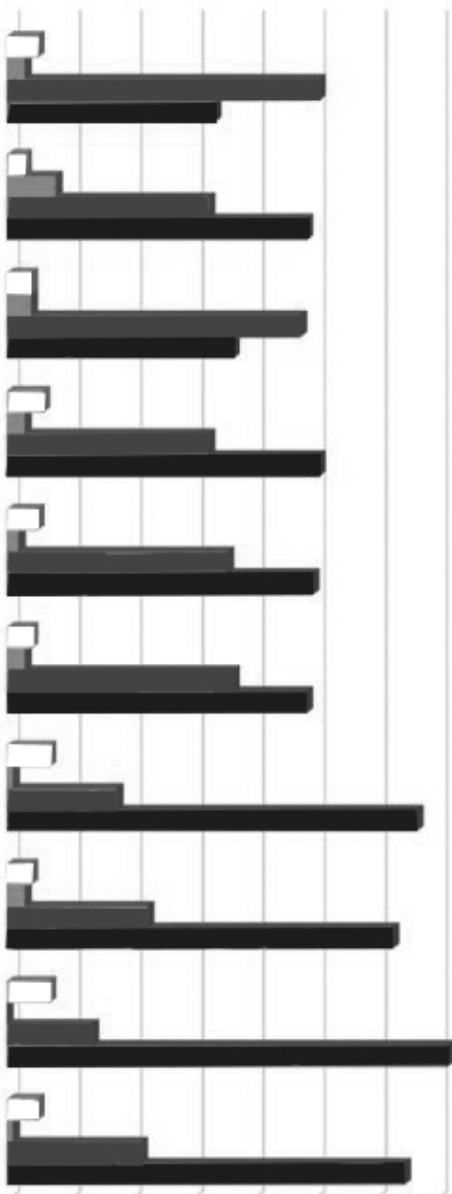

$\begin{array}{lllllllll}0 & 10 & 20 & 30 & 40 & 50 & 60 & 70 & 80\end{array}$

I strongly disagree = I disagree | I agree I strongly agree

Figure 10. Overview of responses of students participating in the project with regard to the competencies 


\section{Competencies Acquired During Implementation of Pedagogic Practicum Students not Participating in the Project}

I have capacity to express empathy and promote social justice

I'm prepared for self-reflection and reassessing personal steotypes and prejudices

I'm prepared to contribute to raising student awareness on the neccessity of their inclusion in the democratic processes

I'm qualified to contribute to overcoming discrimination in schools

I'm qualified to contribute to classroom conflict resolution

I'm qualified to cooperate with social institutions and NGOs

I'm prepared to bulld positive and friendly relations with colleagues of different cultural and ethnic background

I'm prepared to contribute to prevention of violence in schools

I respect diversity with regard to cuture, gender, ethnic, and social affiliation

Tnrough personal example I stand for the idea of equal access to education for all children

¿ I strongly disagree
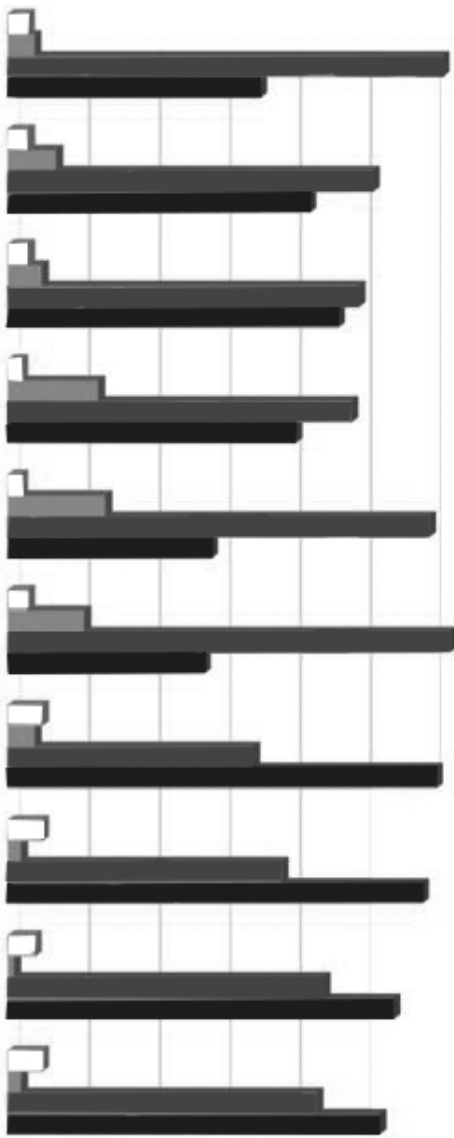

$\begin{array}{lllllll}0 & 10 & 20 & 30 & 40 & 50 & 60\end{array}$ 70

Figure 11. Overview of responses of students not participating in the project with regard to the competencies 
Such results may lead to a conclusion that the implementation of the project Strengthening the Pre-Service Teacher Training System in a Multi-Ethnic Society positively affects the development of intercultural competencies of the students who participated in the project and that the students who did not participate in the project have the need of acquiring additional knowledge, competencies, skills and attitudes for the implementation of the practicum in a multicultural environment. Additionally, the statistical data in the charts show that both categories of students have predominantly answered I agree and I strongly agree with regard to the acquisition of intercultural competencies, which is indicative of the fact that the teacher training curriculum in the Republic of Macedonia is in line with the contemporary educational trends and promotes multicultural education content. In other words, the students should know "how one group of people thinks about another" [16, p. 155].

\section{Analysis of the experiences of teacher training institutions from the Balkans}

A separate Questionnaire was administered among nine professors from different educational institutions in the region. The aim was to screen the implementation of the practicum of the prospective pedagogues, educators and teachers in the multicultural environment in the region. A comparative approach was used to screen the state of affairs in the Republic of Macedonia and in the Balkans. The survey was administered among professors from: Sarajevo International University (Bosnia and Herzegovina), Vranje Faculty of Pedagogy (Serbia), Aleksinac Higher School for Educators (Serbia), Korca Faculty of Pedagogy (Albania), Durres Faculty of Social Sciences (Albania), Tirana University (Albania), Sofia Faculty of Philosophy (Bulgaria), Split Faculty of Philosophy (Croatia) and Zagreb Faculty of Philosophy (Croatia).

The research results have confirmed the Specific Hypothesis B, namely that the bulk of the interviewees share the opinion that their faculties' syllabuses include multicultural education content, although they also consider that there is a need of further pedagogic practicum in a multicultural environment. The findings show that the faculties of pedagogy and philosophy in Serbia, Albania, Bosnia and Herzegovina, Croatia, Bulgaria, including Macedonia enroll students with different ethnic background. All surveyed institutions had been offering curriculum with multi-cultural content for more than 3 years.

The Figure 12 shows the types of practicum implemented by the countries in the region. There is certain diversity with regard to the implementation of the practicum. At the International University in Sarajevo, for instance, the student practicum is implemented in the last 2 years of the studies. At the University of Tirana, the practicum is implemented in the last year of the studies, whereas at the Split Faculty of Philosophy and at the Durres Faculty for Social Sciences, the 


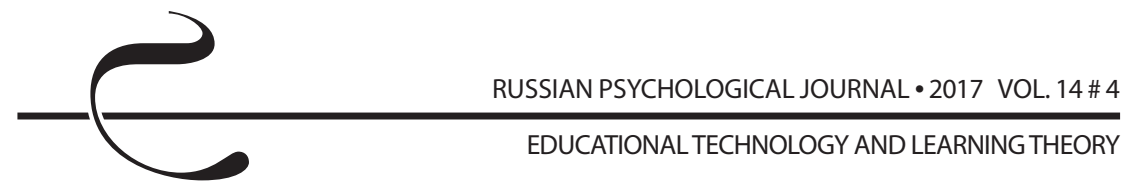

student practicum is implemented in a combined system, different than the offered models.

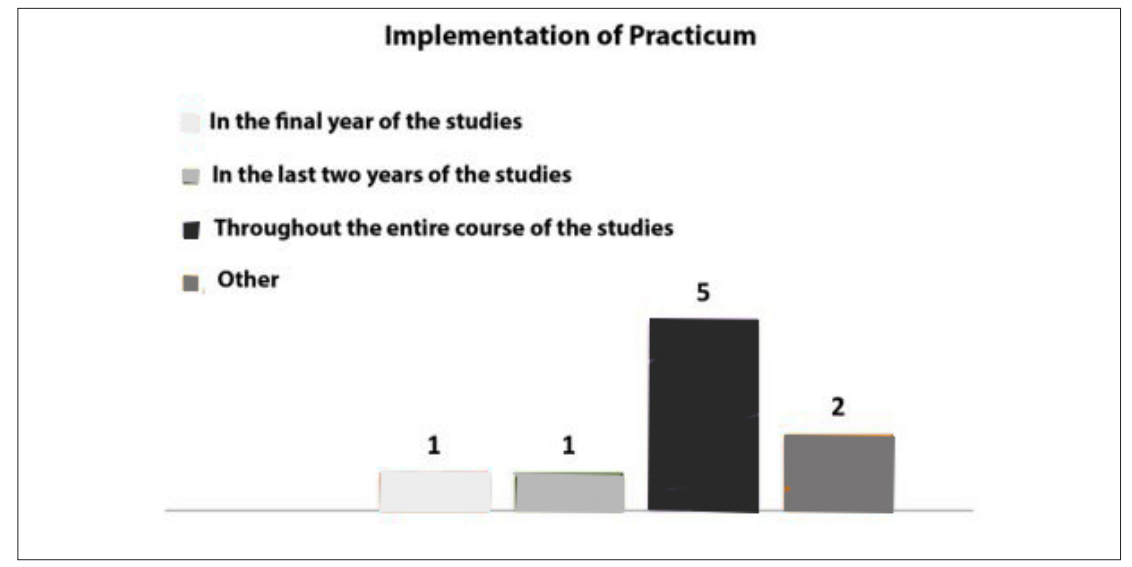

Figure 12. Overview of responses of professors from foreign universities with regard to the duration of the student practicum

Seven institutions in the region (Sarajevo International University, Korca Faculty of Pedagogy, Durres Faculty of Social Sciences, Tirana University, Sofia Faculty of Philosophy, Split Faculty of Philosophy and Zagreb Faculty of Philosophy) make use of a Practicum Implementation Instruction, whereas two institutions do not (Aleksinac Higher School for Educators and the Vranje Faculty of Pedagogy). Across all countries in the region there are schools with mixed ethnic structures. Students in the faculties in Korca, Tirana, Sarajevo, Aleksinac and Vranje may conduct the practical work in-house, whereas the students from the faculties from Sofia, Zagreb, Split and Duress have no such possibility.

Following completion of the practicum, the students from the region are expected to obtain the following competencies:

- implementation of inclusive curriculum based on the needs of all students;

- intercultural approach to lesson planning and preparation;

- heightened tolerance towards the cultural and the ethnic diversity;

- knowledge of the language of the other ethnic communities.

The faculties in Vranje, Korca, Tirana, Sarajevo and Split register the competencies acquired with the student practicum in the addendum to the diploma, unlike the faculties in Zagreb, Sofia, Duress and Aleksinac.

Six of the interviewees (from faculties in Sofia, Zagreb, Split, Sarajevo, Korca and Vranje) have answered positively to the question whether their students have the possibility to conduct practical work in NGOs, whereas three interviewees (from 
the faculties in Aleksinac, Drac and Tirana) have responded negatively. Five of the interviewees (from the faculties in Zagreb, Split, Sarajevo, Tirana and Korca respectively) have answered positively to the question whether their students have participated in projects with multicultural content, and four interviewees (from the faculties in Sofia, Vranje, Aleksinac and Drac) have responded negatively. Students of the institutions which have provided positive answer to the above question had participated in the following education projects with multicultural component:

1. Intercultural Curriculum and Education in Minority Languages.

2. Intercultural Education and European Values.

3. Inclusive Education (with the University of Bologna).

4. Ghost Town 20/20 (Project on the $20^{\text {th }}$ anniversary of Srebrenica genocide).

5. Terre des Hommes (Project with UNICEF).

6. Boys Reading (Erasmus + Project).

The findings of this research show that the implementation of the student practicum at the teacher training faculties in Macedonia has improved as a result of the implementation of the project Strengthening the Pre-Service Teacher Training System in a Multi-Ethnic Society as well as a result of the other project activities of the Education Section with the OSCE Mission to Skopje. Currently, Macedonia does not fall behind any Balkan country (including the EU member states, Croatia and Bulgaria) with regard to the:

- duration of the practicum;

- availability of a practicum implementation instruction;

- implementation of the practicum in multicultural environment;

- implementation of the practicum in the NGO sector;

- curriculum with multicultural modules for strengthening the intercultural competencies of the prospective pedagogues, tutors and teachers.

According to the number of education projects with multicultural component, implemented by the teacher training faculties, Macedonia is the leader in the region. Unlike the students at the institutions in the Balkan region who participated in the research (where at each institution students had the opportunity to participate only in one or maximum two education projects with multicultural component), the students from teacher training faculties in Macedonia, in the last 2 years, have participated in at least five projects, as follows: USAID project in cooperation with MCEC: Interethnic Integration in Education, project of the Loja Centre for Balkan Cooperation, Anchoring Multi-ethnic Youth Work in University Curricula of Future Teachers, the project Mosaic of the Centre for Joint Grounds, which focuses on the multicultural perspectives in the preschool education; the NO project of Sumnal - Tutoring Support for Senior Roma Primary School Students which helped the organization of the pedagogic practicum for the prospective 


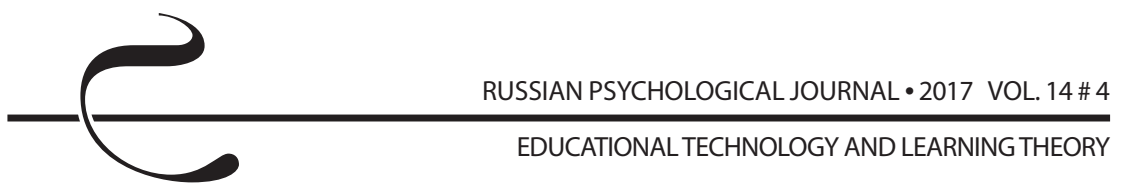

teachers as mentors of Roma children with learning difficulties and the OSCE project Strengthening the Pre-Service Teacher Training System in a Multi-Ethnic Society.

The education projects with multicultural component are implemented internationally, primarily through the organization of international conferences, congresses, and seminars by the teaching training faculties that deal with the issue of multiculturalism in education.

\section{Discussion}

The results of the research show that progress has been made in many segments of the activities implemented as part of the project Strengthening the Pre-Service Teacher Training System in a Multi-Ethnic Society.

The main progress has been noted in the development of the intercultural class teaching competencies of the prospective pedagogues, educators and teachers, who participated in this project. According to the statistical data, this category of students shows a higher degree of development of competences for work in multicultural environment than the category of students who did not participate in the project.

Additionally, the participating students show an evident tendency to open up to people with different experience and ethnic background, make new acquaintances, and in general, communicate without prejudice. It represents a progress in accordance with the newest pedagogical researches [17].

From the other side, this is indicative of the fact that the advantage of the implementation of the practicum in the NGO sector is in the informality of the applied approach.

Of note is also that there is an increasing interest among students for developing seminar and graduate work, essentially based on the perspectives of multicultural education. The OSCE Manual on Social Skills and Responsibilities of the Teachers and School Advisors is widely used across all teacher training faculties as an additional literature for a number of subjects as well as a bibliographical reference in graduate work, focusing on the issue of multiculturalism in education. The Manual has the potential to be used as mandatory literature in the development of seminar works on the subject of multicultural education.

The comparison of the experiences in higher education institutions from the Balkans with regard to the student practicum shows that the teacher training faculties in Macedonia mark progress in the organization and harmonization of the manner of implementation of the practicum in general, as well as in the provision of quality student practicum in the NGO sector and in a multicultural environment. Also, theoretical research shows that, it is perfectly possible and educationally advantageous to involve the student teachers in discussion of which competencies they want their mentor to focus on [18]. 
The analysis of the obtained results shows that more interventions are needed into the syllabus of the teacher training faculties in the region as well as into the capacity building of the prospective pedagogues, educators and teachers for working in multicultural environment. At first, it is necessary to bring together the cultures in the classrooms [19] and to manage the student's behavior [20].

Therefore, our recommendations include the following parameters:

- in line with the commitments of the Ministry of Education and the resolve of the relevant factors of the international community as well as based on the results of the research, i. e. the perceptions of the surveyed students, the teacher training faculties in the Republic of Macedonia should enrich the teacher training syllabus, textbooks and teaching tools with multicultural educational content. It is particularly important that this content is included as a mandatory module. We also recommend that the optional subject Multicultural Education evolves into a mandatory subject, to be included in the curriculum of all teacher training faculties;

- with regard to the possibilities of further strengthening the intercultural competencies of the prospective pedagogues, educators and teachers, we recommend organization of summer schools and student conferences which are likely to enhance the communication dynamics between the students of different cultural and ethnic background;

- the introduction of the Manual for Implementation of the Practicum for the prospective pedagogues, educators and teachers has facilitated the work of the teacher-mentors in the primary and the high schools. However, there is an additional need of defining and specifying the key competencies of the teacher-mentors.

Finally, we would like to note that the multicultural content of the syllabus should encourage dialogue, reconciliation and joint problem resolution particularly with the support of the pedagogues, educators and teachers.

We may conclude that the intercultural and the interethnic relations in the education system of the Republic of Macedonia, inherently and systematically, impose the need of constructive communication and interaction, in line with contemporary educational trends [21]. The implementation of such educational purposes and priorities requires adequate knowledge, skills and mindset of the teachers. It is exceptionally important that the students acquire knowledge for action not only professionally, but also personally, as citizens of the society [22]. Also, "in order to do the best job, teachers need to choose a system of beliefs that direct them so they know which path they will take" [23, p. 23].

Therefore, the activities of the project Strengthening the Pre-Service Teacher Training System in a Multi-Ethnic Society have significantly encouraged the development of the intercultural competencies of the prospective pedagogues, 


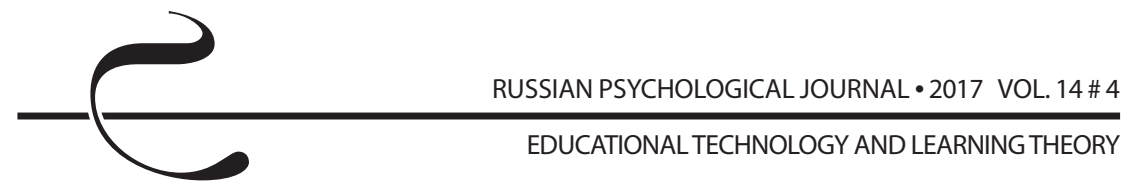

educators and teachers, which ultimately positively affects the capacities of our multicultural and multiethnic society for integration and identification of joint goals and perspectives.

\section{References}

1. Carroll J. Tools for Teaching in an Educationally Mobile World: Internationalisation in Higher Education. New York, Routledge, 2015.

2. Melendez W., Beck V. Teaching Young Children in Multicultural Classrooms: Issues, Concepts, and Strategies. Wadsworth, Cengage Learning, 2013.

3. Brand B. "Sociocultural Consciousness and Science Teacher Education". In M. M. Atwater, M. Russell, M. B. Butler (eds.) Multicultural Science Education: Preparing Teachers for Equity and Social Justice. Berlin, Springer Science \& Business Media, 2014.

4. Sedmak M., Medarić Z. "The Management of Interethnic Relations in the European Context". In M. Sedmak, Z. Medarić, S. Walker (eds.) Children's Voices: Studies of Interethnic Conflict and Violence in European Schools. London, Routledge, 2014.

5. Manning M. L., Baruth L. G., Lee G. L. Multicultural Education of Children and Adolescents. New York, Routledge, 2017.

6. Ramsey P. G. Teaching and Learning in a Diverse World: Multicultural Education for Young Children. New York, Columbia University Teachers College Press, 2015.

7. Roller K. M. "Pre-Service Teachers and Study Abroad: A Reflective, Experiential Sojourn to Increase Intercultural Competence and Translate the Experience into Culturally Relevant Pedagogy". In P. C. Layne and P. Lake (eds.) Global Innovation of Teaching and Learning in Higher Education: Transgressing Boundaries. Cham, Springer, 2015.

8. Brown R. M. K. "Preparing Culturally Competent Teachers through FacultyLed Study Abroad". In Teacher Education: Concepts, Methodologies, Tools, and Applications by Information Resources Management Association. Hershey, PA, Information Science Reference, 2016.

9. Baird B. N. The Internship, Practicum, and Field Placement Handbook. New York, Routledge, 2016.

10. Johnson Ch. S. "Adressing Culturally Consonant Character Development and Research". In K. Gonzalez and R. Frumkin (eds.) Handbook of Research on Effective Communication in Culturally Diverse Classrooms. Hershey, PA, Information Science Reference, 2016.

11. Adams M. "Pedagogical Foundations for Social Justice Education". In M. Adams, L. A. Bell (eds). Teaching for Diversity and Social Justice. New York, Routledge, 2016. 
12. Ghosh R., Galczynski M. Redefining Multicultural Education: Inclusion and the Right to Be Different. Toronto, Canadian Scholars' Press, 2014.

13. Fernandez E. S. "Birthing Culturally Diverse and Racially Just Educational Institutions: Teaching to Transgress and Transform". In E. S. Fernandez (ed.) Teaching for a Culturally Diverse and Racially Just World. Eugene, Wipf and Stock Publishers, 2014.

14. Nikandrov N. D. “Russia: Evolutional Changes against Revolutionary Upheavals". In Y. Wang (ed.) Education Policy Reform Trends in G20 Members. Heidelbelg, Springer, 2013.

15. Bagwell C. L., Schmidt M. E. Friendship in Childhood and Adolescence. New York, The Guilford Press, 2013.

16. Grant C. A. Multiculturalism in Education and Teaching. New York, Routledge, 2015.

17. Verkuyten M., Fleishmann F. “Ethnic Identity among Immigrant and Minority Youth". In A. Rutland, D. Nesdale, Ch. S. Brown (eds.) The Wiley Handbook of Groop Process in Children and Adolescents. Hoboken, Wiley Blackwell, 2017.

18. Hagger H., Mcintyre D., Wilkin M. Mentoring: Perspectives on School-based Teacher Education. New York, Routledge, 2013.

19. Rothstein-Fisch C. Readings for Bridging Cultures: Teacher Education Module. New York, Routledge, 2014.

20. Shepherd T. L., Linn D. Behavior and Classroom Management in the Multicultural Classroom. Thousand Oaks, SAGE Publications, 2015.

21. Bash L., Coulby D. (eds.) Establishing a Culture of Intercultural Education. Cambridge, Cambridge Scholars Publishing, 2016.

22. Matthews S. "Rethinking the Good in Good Global Citizenship: The Ethics of Cosmopolitan Pluralism". In J. B. Rennick and M. Desjardins (eds.) The World is My Classroom: International Learning and Canadian Higher Education. Toronto, University of Toronto Press, 2013.

23. Pang V. O. Diversity and Equity in the Classroom. Boston, Cengage Learning, 2017. 